\title{
THE ANALYSIS OF THE ITERATIONS PROCESS IN THE ELASTO-PLASTIC STRESS MODEL
}

\author{
Joanna Wróbel ${ }^{1}$, Adam Kulawik ${ }^{2}$ \\ Institute of Computer and Information Sciences, Czestochowa University of Technology \\ Czestochowa, Poland \\ joanna.wrobel@icis.pcz.pl,adam.kulawik@icis.pcz.pl
}

\begin{abstract}
In the paper a numerical model of mechanical phenomena in the elastic-plastic state built on the basis of the finite element method is presented. This model gives one the possibility to simulate the stress and strain in the elastic-plastic state with isotropic and kinematic hardening (two-dimensional tasks). The analysis of the influence method for determining the plastic multiplier on the calculation rate is present in the example.
\end{abstract}

\section{Introduction}

Taking into account the elastic-plastic properties of material is more and more common in designing of mechanical systems. Generating plastic strains in the mechanical construction is generally disadvantageous, especially if the areas of occurrence are large. The ideal solution would be to design a structure in which there are no plastic strains. Unfortunately, because of construction and technological limitations, it is impossible. Due to the development of numerical methods it is possible to analyze a structure which takes into account the non-linear nature of the material. Such an analysis allows one to determine the value of plastic strain and areas of their occurrence.

\section{Mathematical and numerical model}

In the mathematical model the equilibrium equation is used in the form

$$
\nabla \circ \boldsymbol{\sigma}+\mathbf{f}=0
$$

where $\boldsymbol{\sigma}$ is the tensor of stress, $\mathbf{f}$ is the vector of volume forces.

Equation (1) is complemented by the constitutive relations in the form of

$$
\Delta \boldsymbol{\sigma}=\mathbf{D} \circ\left(\Delta \varepsilon-\Delta \varepsilon^{p l}\right)
$$

where $\boldsymbol{\varepsilon}$ is the tensor of total strains, $\boldsymbol{\varepsilon}^{p l}$ is the tensor of plastic strains, $\mathbf{D}$ is the tensor of material constants (elastic matrix). 
The weak form of the equilibrium equations (1) is as follows [1]

$$
\int_{\Omega} \sigma_{\alpha \beta} \frac{\partial \Phi}{\partial x_{\beta}} d \Omega=\int_{\Gamma} p_{\alpha} \Phi d \Gamma+\int_{\Omega} f_{\alpha} \Phi d \Omega
$$

where $\Phi=\Phi\left(x_{\alpha}\right)$ are the weight functions, $p_{\alpha}[\mathrm{MPa}]$ is the stress boundary.

The equation (3) is supplemented by appropriate boundary conditions and takes the following form

$$
\sum_{e} \mathbf{K}^{e} \cdot \mathbf{U}^{e}=\sum_{e} \mathbf{R}^{e}, \mathbf{K}^{e}=\int_{\Omega^{e}} \mathbf{B}^{T} \cdot \mathbf{D} \cdot \mathbf{B} d \Omega
$$

where $\mathbf{K}^{e}$ is the element stiffness matrix, $\mathbf{U}^{e}$ the displacement vector, $\mathbf{B}$ is the derivative matrix of the weight functions $\left(\mathbf{B}=\mathbf{B}\left(\frac{\partial \Phi}{\partial x_{\beta}}\right)\right)$ and $\mathbf{R}^{e}$ is the right hand side vector, wherein

$$
\mathbf{R}^{e}=\int_{\Omega^{e}} \mathbf{B}^{T} \cdot \mathbf{D} \cdot \Delta \boldsymbol{\varepsilon}^{p l} d \Omega+\int_{\Gamma^{e}} \Phi \cdot \mathbf{p} d \Gamma+\int_{\Omega^{e}} \Phi \cdot \mathbf{f} d \Omega
$$

\section{Plastic strain, hardening of material}

Modeling stresses in the elastic-plastic state, when the simulated stress exceeds the yield point, it is necessary to take into account the plastic strain in the constitutive relationships (2) [2-5].

In the presented model to determine the plastic strain the associated plastic flow law was used $[2,3]$

$$
\Delta \varepsilon_{\alpha \beta}^{p l}=\Delta \lambda \frac{\partial F\left(\sigma_{\alpha \beta}\right)}{\partial \sigma_{\alpha \beta}}
$$

where $\lambda$ is a scalar plastic multiplier (effective plastic strain), $F$ is the function of plastic flow.

The hardening phenomenon is the change of the plastic surface in the stress space. Classical forms of plastic surface changes are: isotropic, kinematic (anisotropic) and combined hardening [2-6]. In this paper the combined hardening has not been considered.

Isotropic hardening is strengthening of material, in which the surface of plastic flow is symmetrically increased (Fig. 1a), whereas the hypothesis of kinematic hardening takes into account the Bauschinger effect. This hypothesis also assumes that the surface of plastic flow moves as a rigid object without changing its shape (Fig. 1b) $[2,4]$. 
a)

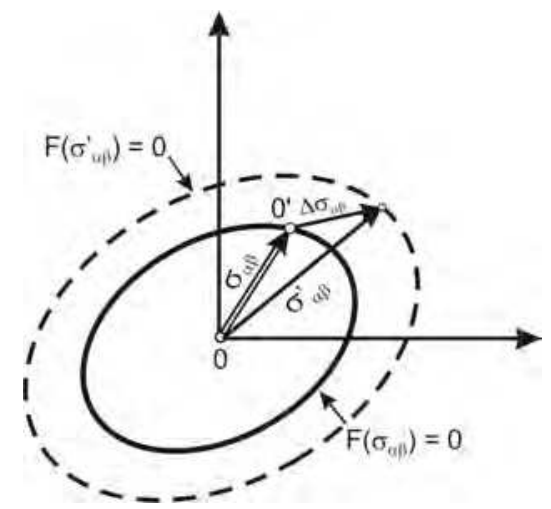

b)

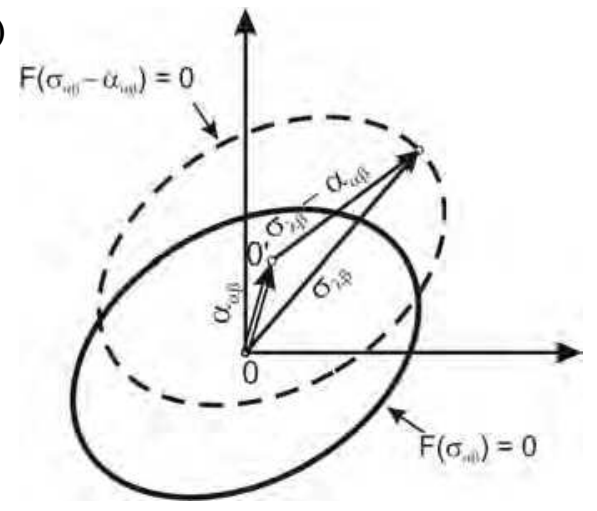

Fig. 1. Graphical interpretation of the hardening: a) isotropic, b) kinematic

\section{Isotropic hardening}

The Huber-Mises-Hencky (HMH) condition for a material with isotropic hardening takes the form

$$
F=\sigma_{e f f}-Y=0
$$

where $\sigma_{\text {eff }}$ is the effective stress, $Y$ is the flow stress.

The effective stress is defined as $[2,3,5]$

$$
\sigma_{e f f}=\sqrt{\frac{3}{2} \sigma_{\alpha \beta}^{D} \sigma_{\alpha \beta}^{D}}
$$

where $\sigma_{\alpha \beta}^{D}$ is the deviatoric stress tensor $\left(\sigma_{\alpha \beta}^{D}=\sigma_{\alpha \beta}-\sigma_{\gamma \gamma} \delta_{\alpha \beta} / 3\right), \delta_{\alpha \beta}$ is known as the Kronecker delta.

The derivation of the equation (7) of stress tensor coordinates and the (8) equation takes the form

$$
\frac{\partial F}{\partial \sigma_{\alpha \beta}}=\frac{3 \boldsymbol{\sigma}^{\mathbf{D}}}{2 \sigma_{e f}}=\frac{3 \boldsymbol{\sigma}^{\mathbf{D}}}{2 Y}
$$

Substituting (9) into (6)

$$
\Delta \varepsilon^{p l}=\Delta \lambda \frac{3 \boldsymbol{\sigma}^{\mathbf{D}}}{2 Y}
$$

Introducing (10) into constitutive relationship (2) and appropriate differentiation of the plasticity condition (7) leads to the scalar multiplier of the plasticity equation. For isotropic hardening this factor is as follows 


$$
\Delta \lambda=2 Y \frac{3 \boldsymbol{\sigma}^{\mathbf{D}} \circ \mathbf{D} \circ \Delta \boldsymbol{\varepsilon}}{9 \boldsymbol{\sigma}^{\mathbf{D}} \circ \mathbf{D} \circ \boldsymbol{\sigma}^{\mathbf{D}}+4 Y \kappa \sigma_{e f f}}
$$

where $\kappa[\mathrm{MPa}]$ is the hardening modulus [2].

\subsection{Kinematic hardening}

In the hypothesis of kinematic hardening the offset plastic surface is described by the following equation $[2,5,6]$

$$
F\left(\sigma_{e f f}\left(\boldsymbol{\sigma}^{\mathbf{D}}-\boldsymbol{\alpha}\right), Y_{0}\right)=0
$$

where $\alpha_{\alpha \beta}$ is the tensor representing the displacement of the center of the plastic surface (kinematics of hardening).

The HMH condition in this case has the form (comp. (7))

$$
\sqrt{3\left(\boldsymbol{\sigma}^{\mathbf{D}}-\boldsymbol{\alpha}\right)\left(\boldsymbol{\sigma}^{\mathbf{D}}-\boldsymbol{\alpha}\right) / 2}-Y_{0}=0
$$

where $Y_{0}$ is the yield point.

The tensor of displacement of the center the plastic surface $(\boldsymbol{\alpha})$ is written as

$$
\boldsymbol{\alpha}=\frac{2}{3} \kappa \varepsilon^{p l}
$$

Analogously to the case of isotropic hardening, in the kinematics hardening is

$$
\Delta \boldsymbol{\varepsilon}^{p l}=\frac{3\left(\boldsymbol{\sigma}^{\mathbf{D}}-\boldsymbol{\alpha}\right)}{2 Y_{0}}
$$

After all, the equation for a scalar plastic multiplier for kinematic hardening has the form

$$
\Delta \lambda=\frac{2}{3} Y \frac{\left(\boldsymbol{\sigma}^{\mathbf{D}}-\boldsymbol{\alpha}\right) \circ \mathbf{D} \circ \Delta \boldsymbol{\varepsilon}-\Delta \boldsymbol{\alpha}\left(\boldsymbol{\sigma}^{\mathbf{D}}-\boldsymbol{\alpha}\right)}{\left(\boldsymbol{\sigma}^{\mathbf{D}}-\boldsymbol{\alpha}\right) \circ \mathbf{D}\left(\boldsymbol{\sigma}^{\mathbf{D}}-\boldsymbol{\alpha}\right)}
$$

The scalar plastic multiplier in the model of an isotropic and kinematic hardening can be determined by using the Newton-Raphson method [1,7].

\section{Numerical simulation}

Two tasks of the numerical simulation of stresses in the elastic-plastic state were realized. For the calculation the two-dimensional area with dimensions of $0.1 \times 0.1 \mathrm{~m}$ (squared) was taken into account, which was divided into a regular 
geometry consisting of triangular elements (1444 elements, 761 nodes, Fig. 2). It was assumed that the Young's modulus $E=2 \times 10^{5} \mathrm{MPa}$, the hardening modulus $\kappa=2.2 \times 10^{4} \mathrm{MPa}$ and the Poisson's ratio $v=0.3$. The calculations have been done for material with isotropic and kinematic linear hardening. In the subsequent iterations the scalar plastic multiplier was determined by the direct method (formulas (11) and (16)) and the Newton-Raphson method. In the second example it is assumed that the accurate solution is found through calculations obtained using the method of Newton-Raphson. The approximation error of the end of the iterations was assumed as $\operatorname{Err}^{i t}=\left(\sigma_{\text {eff }}^{e l} / Y^{e l}\right)<1+1 \times 10^{-8}$.

The accuracy of the calculation for the results of numerical solutions, and the number of iterations for the isolated cases are compared.

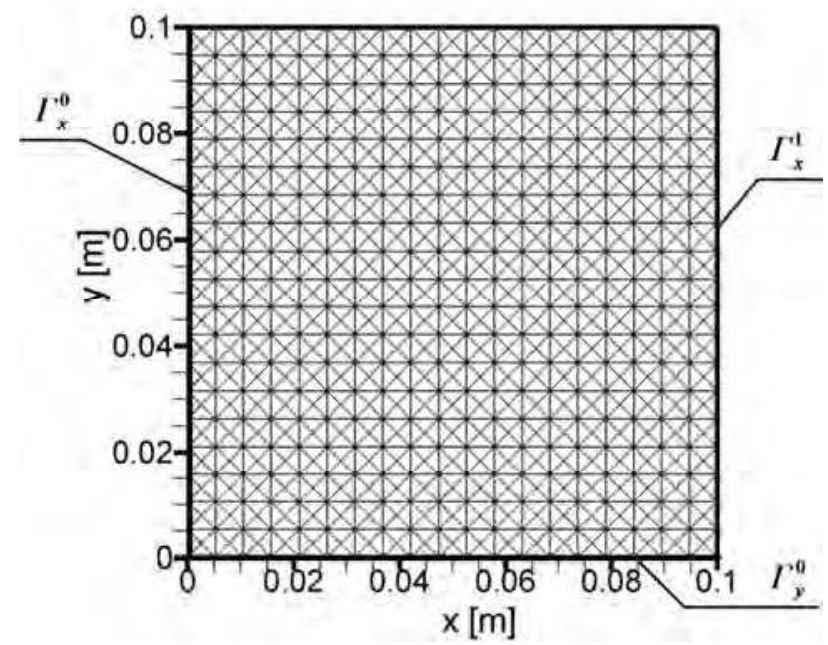

Fig. 2. The considered geometry with the finite element mesh

The tasks were solved with the assumption of plane stress state $[1,2]$.

\section{Example 1}

It was assumed, that the displacement of the edges $\Gamma_{x}^{0}$ and $\Gamma_{y}^{0}$ are equal $U_{x}(0, y)=0, U_{y}(x, 0)=0$. On the boundary $\Gamma_{x}^{1}$ the condition of the constant increment of boundary load was assumed for the next steps $\left(p_{x}=40 \mathrm{MPa}\right)$. After 10 steps the sign of load was changed on $\left(p_{x}=-40 \mathrm{MPa}\right)$. The error of the end of the iterations in the search of the surface of the plastic flow was assumed as $E r r^{i t}=\left(\sigma_{\text {eff }}^{e l} / Y^{e l}\right)<1+1 \times 10^{-4}$. The obtained results for the steps of growth stresses, in which the plastic flow occurred, are shown in Figures 3 and 4. 

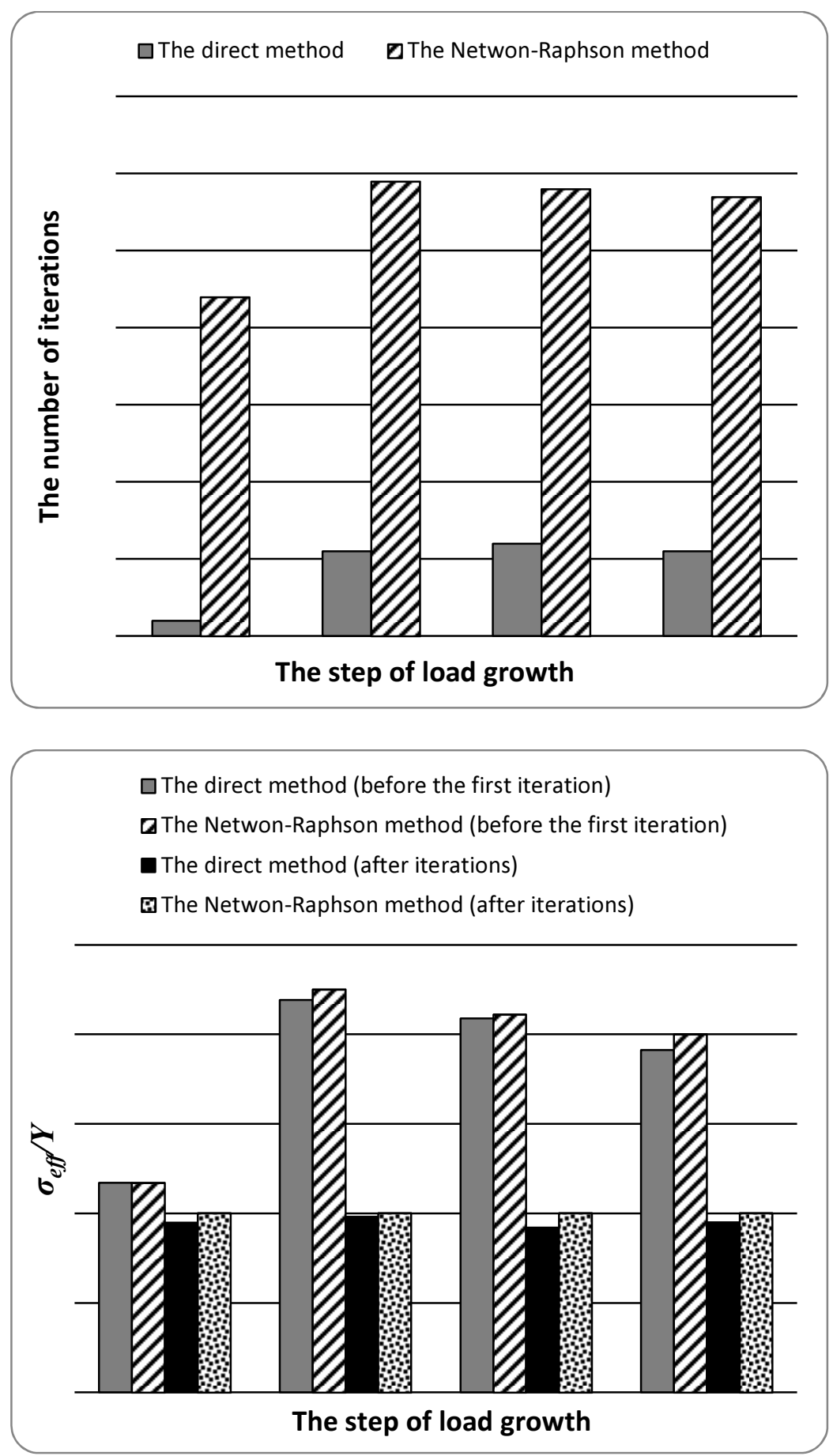

Fig. 3. The results of calculations for the isotropic hardening 

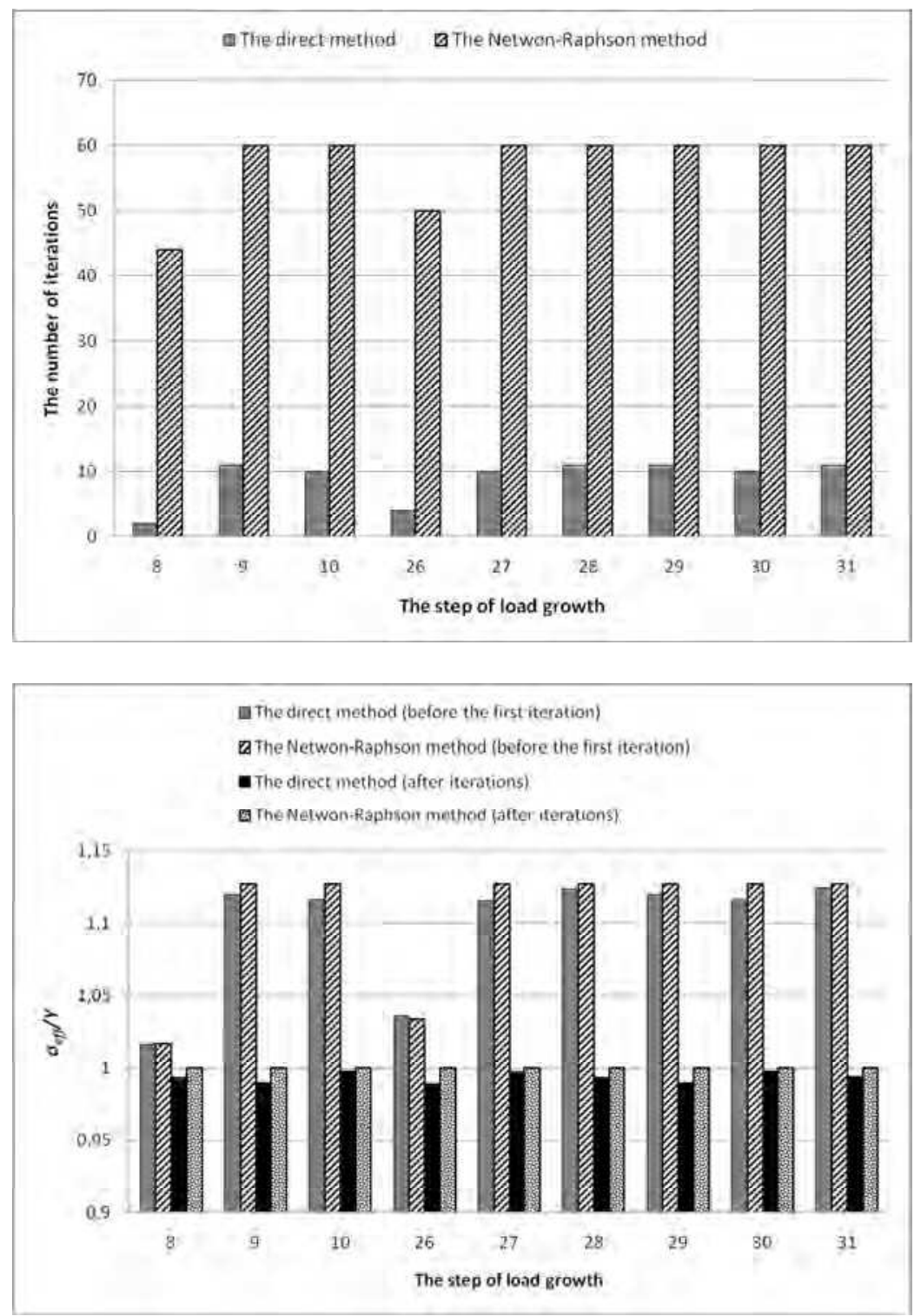

Fig. 4. The results of calculations for the kinematic hardening

\section{Example 2}

In the presented simulation of stresses, it was assumed that the displacement at the edge $\Gamma_{x}^{0}$ was $U_{x}(0, y)=0, U_{y}(0, y)=0$ (fixed). On the boundary $\Gamma_{x}^{1}$ it was assumed that the growth of displacement in every step of the load was $U_{x}(0.1, y)=2 \times 10^{-5} \mathrm{~m}$. After 10 steps the sign of displacement growth was changed 
on $U_{x}(0.1, y)=-2 \times 10^{-5} \mathrm{~m}$. The error of the end of the iterations in this case was $\operatorname{Err}^{i t}=\left(\sigma_{\text {eff }}^{e l} / Y^{e l}\right)<1+1 \times 10^{-2}$. The obtained results are shown in Figures 5 and 6.
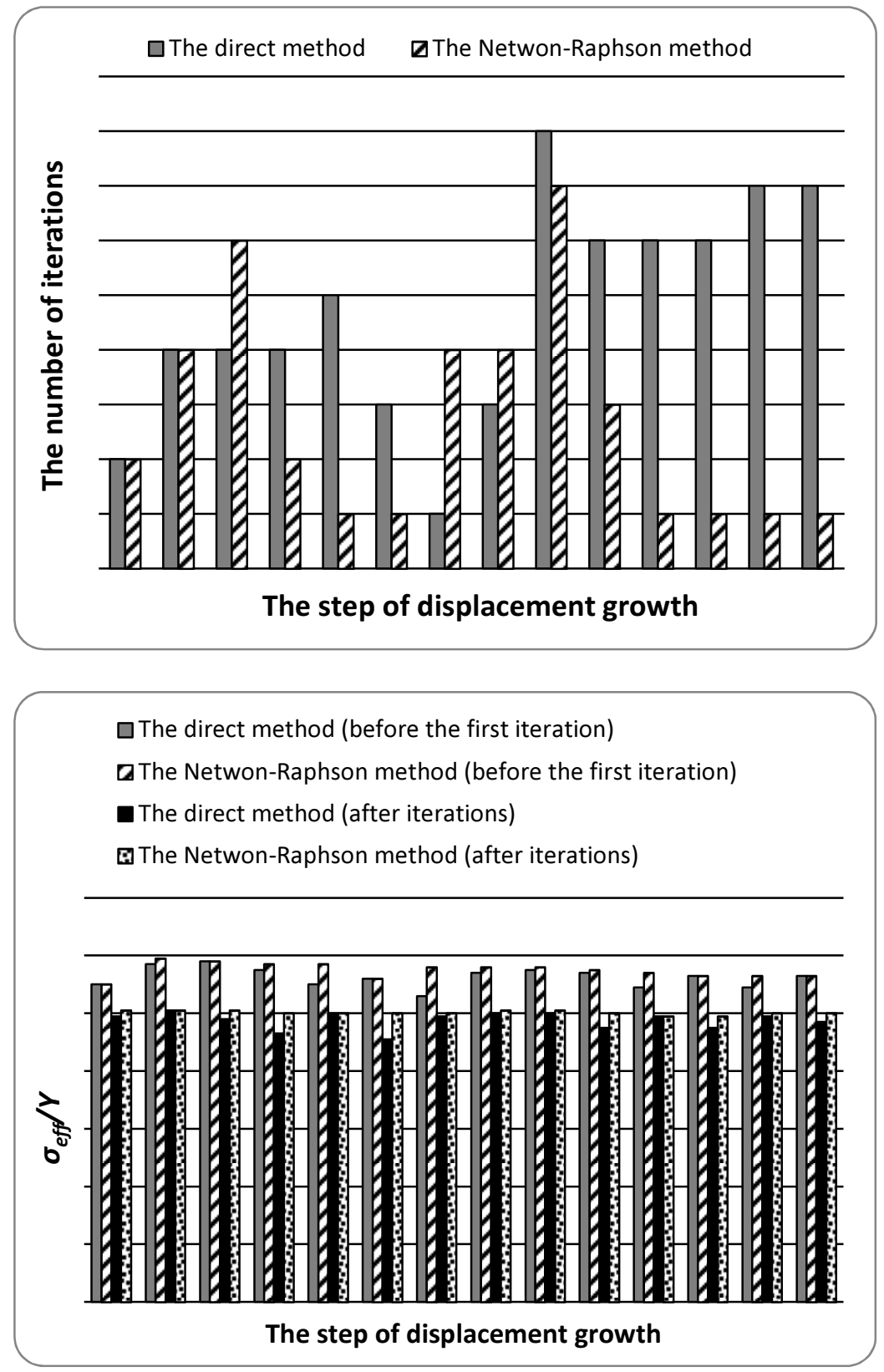

Fig. 5. The results of calculations for the isotropic hardening 

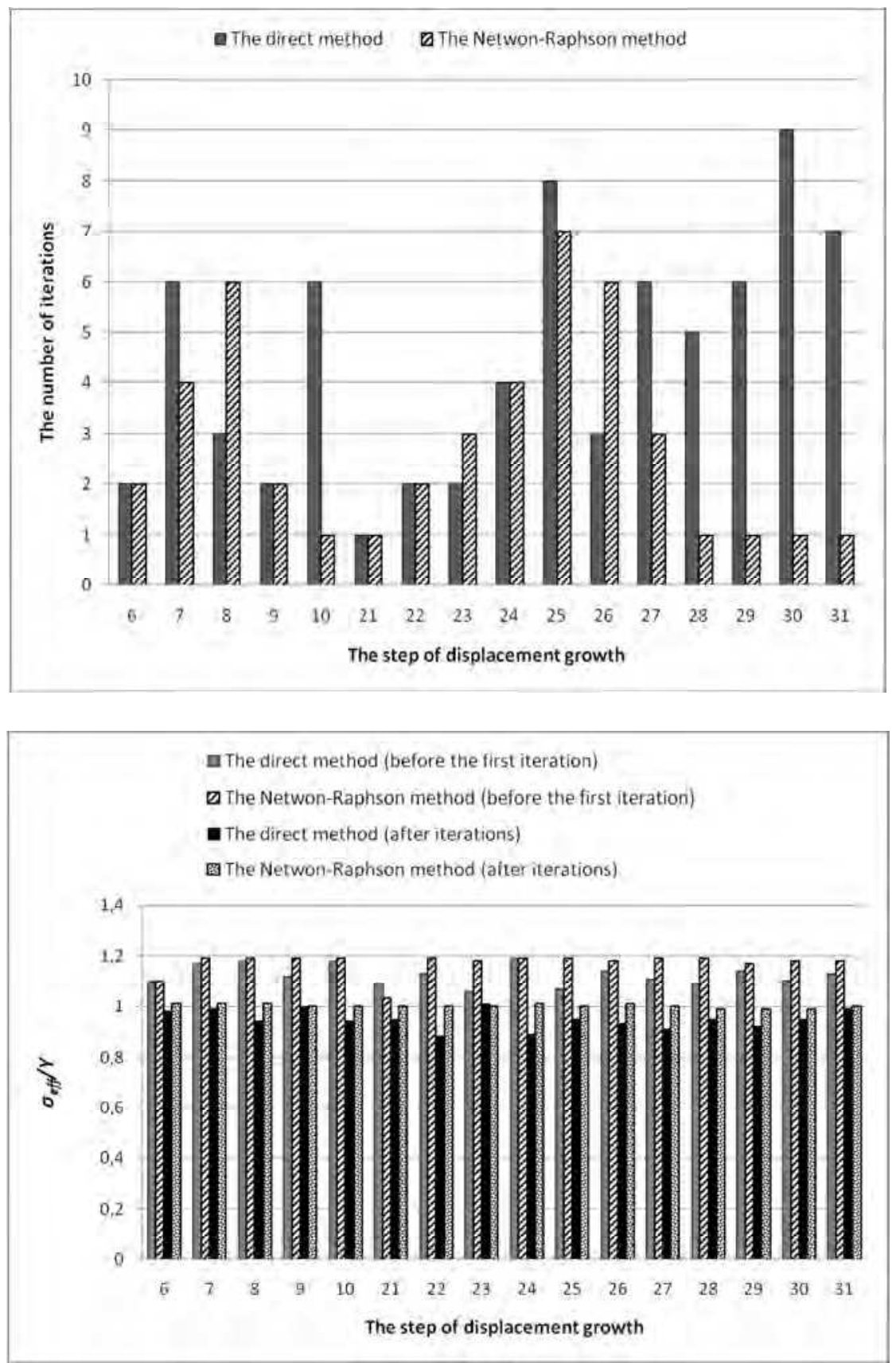

Fig. 6. The results of calculations for the kinematic hardening

After solving tasks, the fields of effective stresses (Figs. 7 and 8) were made. In Figures $7 \mathrm{~b}, 7 \mathrm{c}$, and $8 \mathrm{~b}, 8 \mathrm{c}$ the absolute differences between the exact and the approximate solution were presented. 
a)

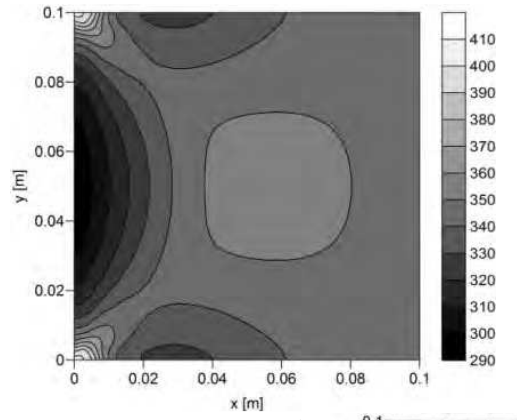

b)

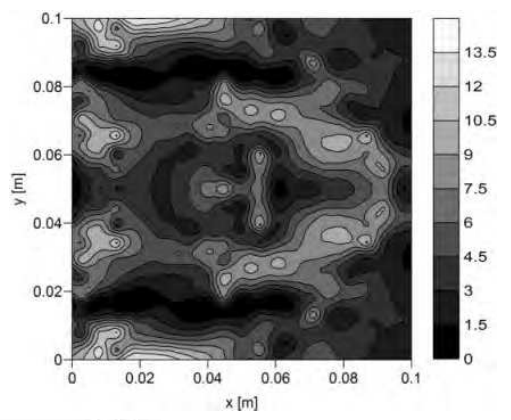

c)

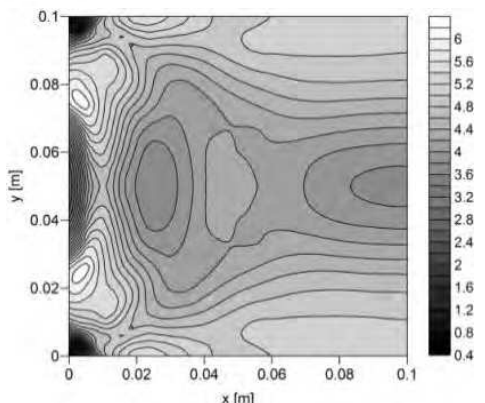

Fig. 7. The effective stress (exact solution) (a) and the absolute difference, between the effective stress, obtained from the assumption the isotropic hardening: b) the direct method, c) the Newton-Raphson method

a)

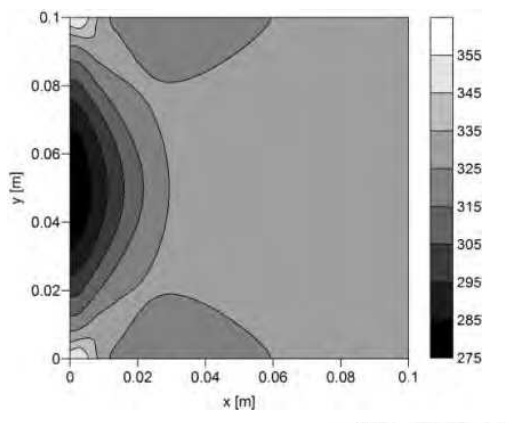

b)

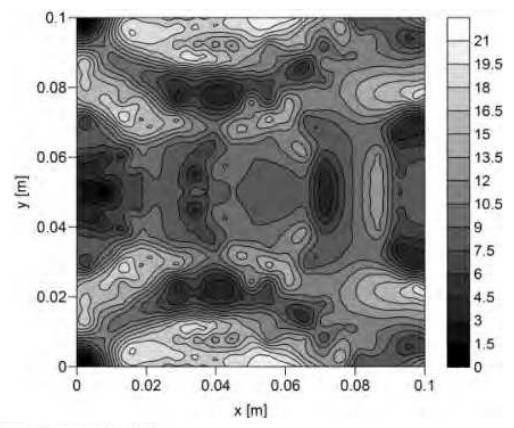

c)

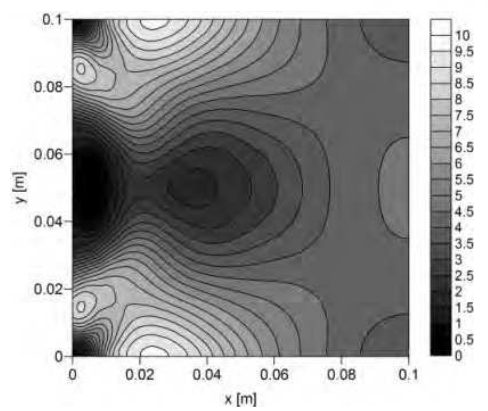

Fig. 8. The effective stress (exact solution) (a) and the absolute difference, between the effective stress, obtained from the assumption the kinematic hardening: b) the direct method, c) the Newton-Raphson method 


\section{Conclusions}

The paper presents an application of finite element methods for solving mechanics problems. The numerical simulation of stresses was performed in the elastic-plastic state for material with isotropic and kinematic hardening. The scalar plastic multiplier was determined using the direct method and the Newton-Raphson method, then the results of the calculations were compared (Figs. 3-6).

For absolute differences concerning the effective stress (Figs. 7 and 8) the normalized mean square error (NMSE) has been assumed [8]

$$
N M S E=\sum_{x=1}^{M} \sum_{y=1}^{N}[f(x, y)-\hat{f}(x, y)]^{2} / \sum_{x=1}^{M} \sum_{y=1}^{N}[f(x, y)]^{2}
$$

NMSE error values for each of the chosen methods of determining the plastic multiplier and for different types of hardening are equal to:

- for the isotropic hardening (the direct method) NMSE $=32.3043 \times 10^{-5}$,

- for the isotropic hardening (the Newton-Raphson method) NMSE = $=18.4789 \times 10^{-5}$,

- for the kinematic hardening (the direct method) NMSE $=144.7253 \times 10^{-5}$,

- for the kinematic hardening (the Newton-Raphson method) NMSE = $=24.9105 \times 10^{-5}$.

Analyzing the results of numerical tests it can be seen that the use of the Newton-Raphson method gives less diversification of errors (Figs. 7 and 8), than when using the direct method. In the case of load on the boundary by the stress (Example 1) the number of iterations is many times greater in Newton-Raphson method, than in the direct method (Figs. 3 and 4). In the case of the load by the displacement of the boundary (Example 2) the difference between temporal complexity (the number of iterations) for these two methods is negligibly small (Figs. 5 and 6). The use of Newton-Raphson method leads to greater accuracy of the calculations, although in some cases this method causes an unacceptable time of calculations (Figs. 3 and 4).

\section{References}

[1] Zienkiewicz O.C., Taylor R.L., The finite element method, Butterworth-Heinemann, Fifth edition, vol. 1-3, New York 2000.

[2] Bednarski T., Mechanika plastycznego płynięcia w zarysie, WN PWN, Warszawa 1995.

[3] Gabryszewski Z., Gronostajski J., Mechanika procesów obróbki plastycznej, PWN, Warszawa 1991.

[4] Ganczarski A., Skrzypek J., Plastyczność materiałów inżynierskich. Podstawy, modele, metody i zastosowania komputerowe, Wydawnictwo Politechniki Krakowskiej, Kraków 2009.

[5] Kleiber M., Metoda elementów skończonych w nieliniowej mechanice kontinuum, PWN, Warszawa-Poznań 1985. 
[6] Bokota A., Modelowanie hartowania stali narzędziowych. Zjawiska cieplne, przemiany fazowe, zjawiska mechaniczne, Wydawnictwo Politechniki Częstochowskiej, Częstochowa 2012.

[7] Caddemi S., Martin J.B., Convergence of the Newton-Raphson algorithm in elastic-plastic incremental analysis, Int. J. Numer. Meth. Eng. 1991, 31, 177-191.

[8] Skarbek W., Multimedia. Algorytmy i standardy kompresji, Akademicka Oficyna Wydawnicza PLJ, Warszawa 1998. 